OPEN ACCESS

Edited by:

Umberto Malapelle,

University of Naples Federico II, Italy

Reviewed by:

Valerio Gristina,

University of Palermo, Italy

Francesco Passiglia,

University of Turin, Italy

*Correspondence:

Xue Meng

mengxuesdz@163.com

Jinming $Y_{L}$

sdyujinming@163.com

Specialty section:

This article was submitted to

Thoracic Oncology,

a section of the journal

Frontiers in Oncology

Received: 07 September 2020 Accepted: 09 November 2020 Published: 18 December 2020

Citation:

Wu L, Ke L, Zhang Z, Yu J and Meng X (2020) Development of EGFR TKIs and Options to Manage Resistance of

Third-Generation EGFR TKI

Osimertinib: Conventional Ways and Immune Checkpoint Inhibitors.

Front. Oncol. 10:602762. doi: 10.3389/fonc.2020.602762

\section{Development of EGFR TKIs and Options to Manage Resistance of Third-Generation EGFR TKI Osimertinib: Conventional Ways and Immune Checkpoint Inhibitors}

\author{
Leilei $W u^{1,2}$, Linping $\mathrm{Ke}^{2}$, Zhenshan Zhang ${ }^{1}$, Jinming $\mathrm{Yu}^{2 *}$ and Xue $\mathrm{Meng}^{2 *}$ \\ ${ }^{1}$ Department of Radiation Oncology, School of Medicine, Shandong University, Jinan, China, ${ }^{2}$ Department of Radiation \\ Oncology, Shandong Cancer Hospital and Institute, Shandong First Medical University and Shandong Academy of Medical \\ Sciences, Jinan, China
}

Epidermal growth factor receptor tyrosine kinase inhibitors (EGFR TKIs) have been firstline therapy in the treatment of non-small cell lung cancer (NSCLC) harboring EGFR sensitive mutations. Progression inevitably happens after 10-14 months of first- or second-generation EGFR TKIs treatment for acquired resistance. Owing to the successful identification of EGFR T790M, third-generation EGFR TKIs such as osimertinib were developed to target such resistance mutation. Nowadays, osimertinib has shown its efficacy both in first-line and second-line after resistance to previous generations of TKI treatment of EGFR-mutant NSCLC. However, drug resistance also emerges on third-generation EGFR TKls. Multiple mechanisms of acquired resistance have been identified, and some novel strategies were reported to overcome thirdgeneration TKI resistance. Immune checkpoint inhibitors (ICls) have dramatically changed the prognosis of selected patients. For patients with EGFR-addicted metastatic NSCLC, ICls have also revealed a potential role. In this review, we will take stock of mechanisms of acquired resistance to third-generation TKIs and discuss current challenges and future perspectives in clinical practice.

Keywords: EGFR TKI resistance, osimertinib, combination (combined) therapy, immune check inhibitor, mechanisms of resistance, tumor immune environment, molecular biomarkers

\section{INTRODUCTION}

Somatic alterations in epidermal growth factor receptor (EGFR) lead to abnormal activation of receptor tyrosine kinases (RTKs) signaling and occur in approximately $50 \%$ of Asian non-small cell lung cancer (NSCLC) patients and 15\% (10-16.6\%) of Caucasian NSCLC patients (1-6). EGFR, encoded by EGFR, also referred to as ErbB1/HER1, a member of human epidermal growth factor receptor (HER)/ErbB family, is a transmembrane RTK, followed by ErbB2 (HER2/neu), ErbB3 (HER3), and ErbB4 (HER4) $(1,7)$. Exons 18-24 encode the EGFR kinase domain and the most 
common alterations are deletions in exon 19 (ex19del, about 44\%) and point mutations in exon 21 (L858R, about 41\%), known as common mutations or classical mutations $(1,4,8)$. Uncommon EGFR mutations in exons 18-21, such as L861X, G719X, and S768I, account for approximately $10 \%$ of EGFR mutations, also called atypical EGFR mutations $(9,10)$. These mutations increase activity of EGFR and then activate three main downstream signaling pathways: mitogen-activated protein kinases (MAPK)/ extracellular signal-regulated kinases (ERK), phosphatidylinositol 3-kinase (PI3K)/AKT/mTOR, and interleukin 6 (IL-6)/Janus kinase (JAK)/signal transducer and activator of transcription 3 (STAT3) signaling pathways $(7,8,11)$. These signaling cascades relate RTK activity to increased proliferation, motility, migration, survival, and anti-apoptotic cellular responses and facilitate genesis and development of $\operatorname{NSCLC}(8,11)$.

In first-line treatment, first-generation EGFR TKIs erlotinib, gefitinib, and icotinib and second-generation afatinib and dacomitinib have exhibited advantages over various platinumbased chemotherapy in phase III trials for the treatment of patients with advanced NSCLC with activating EGFR mutations. However, most patients treated with first and second-generation EGFR TKIs inevitably develop acquired resistance through various mechanisms after a median period of $10-14$ months $(9,12,13)$. The most common mechanism is EGFR T790M mutation in exon 20 which accounts for approximately $50 \%$ of all EGFR TKIs resistance in NSCLC patients, more than half of which arises from T790M mutation in exon $20(12,13)$. In summary, the two generations are considered ineffective in management of T790M-positive NSCLC although second-generation shows some special effects. In recent years, multiple third-generation mutation-selective EGFR TKIs have been developed to overcome aforementioned obstacles, such as WZ4002, rociletinib (CO1686), osimertinib (AZD9291), and Almonertinib (HS-10296) (14-17). Based on the AURA trials, osimertinib is currently a standard of care for EGFR-mutant NSCLC patients with acquired resistance to first- or second- generation EGFR-TKIs owing to the T790M mutation (18-21). Moreover, the phase III FLAURA trial provides another option for first-line treatment of patients with EGFR-activating mutations, which showed the superiority of osimertinib over firstgeneration EGFR TKIs as a first-line treatment (22). However, despite their efficacy, acquired resistance will also eventually emerge. It seems that standard chemotherapy is the only way to go after osimertinib resistance, but novel strategies, such as newer generation TKIs and immune checkpoint inhibitors (ICIs), have been emerging, and a variety of combined strategies have been explored to optimize all treatment lines in recent years, as will be discussed later.

This review summarizes the current mechanisms of acquired resistance to osimertinib and discusses the promising strategies to manage such problems on the basis of rationalities and controversies in the transition from preclinical investigation to clinical practice. We highlight clues and challenges regarding future combination therapeutic options in treatment of EGFRmutant NSCLC and put emphasis on ICIs, wishing to give some references to clinical practice.

\section{EVOLUTION OF TKIS TO THIRD- GENERATION}

\section{Osimertinib}

Multiple third-generation EGFR TKIs were reported to inhibit T790M mutation, while exhibiting activity against EGFR ex19del and L858R mutation and sparing the inhibition of wild-type receptors (14-17). Compared to the other inhibitors, osimertinib has shown great superiority and was the only one approved by the Food and Drug Administration (FDA) and European Medicines Agency (EMA) to date (18-23). The initial phase I/ II study AURA and extensive phase II study AURA2 demonstrated impressive and exciting responses of osimertinib in EGFR-mutant advanced NSCLC patients previously treated with EGFR TKIs (first- or second-generation), especially in patients with T790M mutation $(19,20)$. The subsequent phase III study AURA3 continued to confirm advantages of osimertinib both in efficacy and toxicity profile in EGFR T790M mutation-positive advanced NSCLC patients who progressed on first-line EGFR TKI therapy, in comparison to platinum plus pemetrexed chemotherapy (21). Then, the phase III trial FLAURA of osimertinib in previously untreated, EGFR mutation-positive (ex19del or L858R), advanced NSCLC compared to standard EGFR TKIs suggested its efficacy at delaying acquired resistance with a median progression free survival (PFS) of 18.9 months and overall survival (OS) of 38.6 months and less adverse events of grade 3 or higher in first-line therapy (22). Hence, gefitinib, erlotinib, afatinib, dacomitinib, and osimertinib have been recommended as first-line treatment by NCCN (category 1) (18).

In general, all EGFR TKIs play their respective values in clinical practice. For example, improvements were detected in brain metastases under the role of afatinib and osimertinib both in preclinical and clinical studies, while other EGFR TKIs produce limited efficacy $(23,24)$. Besides, osimertinib is the first choice for patients with primary T790M mutation $(16,22)$. In terms of uncommon mutations excluding the exon 20 insertion (ex20ins), osimertinib demonstrated favorable activity with a high response rate, an encouraging PFS, a long duration of overall response (DOR) and manageable toxicity (25). Nevertheless, only a small number of patients were assessed and objective response rates (ORRs) across specific uncommon mutation type were quite diverse with osimertinib treatment (25). Available data regarding the efficacy of first- or second-generation TKIs in NSCLC patients with uncommon EGFR mutations are inconsistent resulting from retrospective or post hoc analyses. In a post hoc analysis of afatinib data from the LUX-Lung 2, LUX-Lung 3, and LUX-Lung 6 trial populations reported by Yang et al., ORR was $71 \%$ and PFS was 11 months among patients with uncommon EGFR mutations with afatinib treatment, except for those with the T790M or ex20ins mutation (10). The third most common rare mutation is exon 20 S768I mutation, whose clinical data are inconsistent among studies. Cho et al. demonstrated an ORR of $38 \%$ with a PFS of 12.3 months in patients with just the S768I mutation (25). However, Chiu et al. reported an ORR of $100 \%$ and median PFS was 14.7 months with afatinib in patients with only the S768I mutation (26). 
In conclusion, both afatinib and osimertinib showed relatively high efficacy in uncommon EGFR mutations and can be considered as a treatment option based on current data. More studies with large number of patients are needed, and we must give a synthetic consideration in drug choice, such as activity, toxicity, mutation type and CNS metastasis. On the other hand, in view of ultimate drug resistance of osimertinib, more studies need to be conducted to compare benefits of latter-line to front-line. We also need to recognize that quite a few patients may not have the opportunity to take a biopsy again and change drugs after drug resistance.

\section{Other Prospective Third-Generation Drugs}

Almonertinib has been approved recently by National Medical Products Administration (NMPA) in China, exhibited a median PFS of 12.3 months, acceptable toxicity and an ORR of $68.9 \%$ in second-line treatment of EGFR-mutant NSCLC after drug resistance in the phase II APOLLO trial (17). Lazertinib (YH25448), another mutant-selective third-generation EGFR inhibitor, was more effective and better tolerated than osimertinib in preclinical data (27). A phase I-II study (NCT03046992), enrolling patients with advanced NSCLC harboring activating mutations of EGFR who had progressed after EGFR TKI therapy, had further proved its tolerable safety profile and promising clinical activity (28). A phase 2 dose extension part is ongoing. Additionally, Cho et al. have recently reported the preliminary result of the phase I CHRYSALIS study (NCT02609776) that the ORR of 23 Part 1 patients receiving the combination of amivantamab (JNJ61186372, EGFR-MET bispecific antibody) with lazertinib was $43.5 \%$, and the safety profile was manageable (29). Abivertinib (AC0010) and alflutinib (AST2818) are also promising thirdgeneration drugs, and we expect more results.

\section{ACQUIRED RESISTANCE TO THIRD- GENERATION EGFR TKIS}

Mechanisms of resistance to first- and second-generation EGFR TKIs have been well researched (Figure 1). Compared to previous generations, quite a few resistance mechanisms remain unknown and deserve further study. Besides, EGFR T790M mutation alone rarely induces resistance to osimertinib. Resistance occurs with a PFS of 18.9 months by treatment of osimertinib used in first-line, including EGFR-dependent and EGFR-independent resistance $(22,30-32)$. A study of mechanisms of acquired resistance to osimertinib given initially or at relapse in patients with EGFR-mutant NSCLC identified on next generation sequencing (NGS) from tumor tissue, presented at ASCO 2019, reported that resistance mechanisms to initial and later-line osimertinib are distinct from each other (33). Firstly, 59\% of resistance mechanisms to firstline osimertinib were uncertain, but such part only made up $25 \%$ in patients receiving later-line osimertinib (33-35). Then, only $7 \%$ of patients receiving initial osimertinib developed EGFR-dependent resistance, contrary to a proportion of $34 \%$ in second-line (33-35). Additionally, histologic transformation/phenotypic change, including squamous cell carcinoma (SCC) histologic transformation, small-cell lung cancer (SCLC) histologic transformation and epithelial-tomesenchymal transition (EMT), was a dominant resistance mechanism, particularly in first-line setting, and they suspected that EGFR-independent resistance may emerge earlier than EGFRdependent resistance (33-36). Of course, some resistance mechanisms in early stages of research may play a part both in front-line and latter-line settings, and we have difficulty in classifying them precisely.

\section{First Line}

Among the EGFR-dependent resistant population, C797S/G and L718Q take up a high proportion, followed by some other rare mutations, such as G724S, S768I, E709K, L692V and L798 (30$32,34)$. The frequency of the C797S mutation was $7 \%$, a tertiary mutation in exon 20 of EGFR, the second most frequent mechanism, only behind MET amplification, when osimertinib was given in first-line (34). Such mutation has been not only detected in osimertinib resistant patients, but also in patients with EGFR T790M treated with rociletinib, olmutinib, and narzatinib $(30-35,37)$. Given that the mutation is located in the kinase-binding site, it possibly abrogates the binding activity of osimertinib to EGFR (30-34).

Among the EGFR-independent mechanisms of resistance to third-generation TKIs, MET amplification, HER2 amplification,
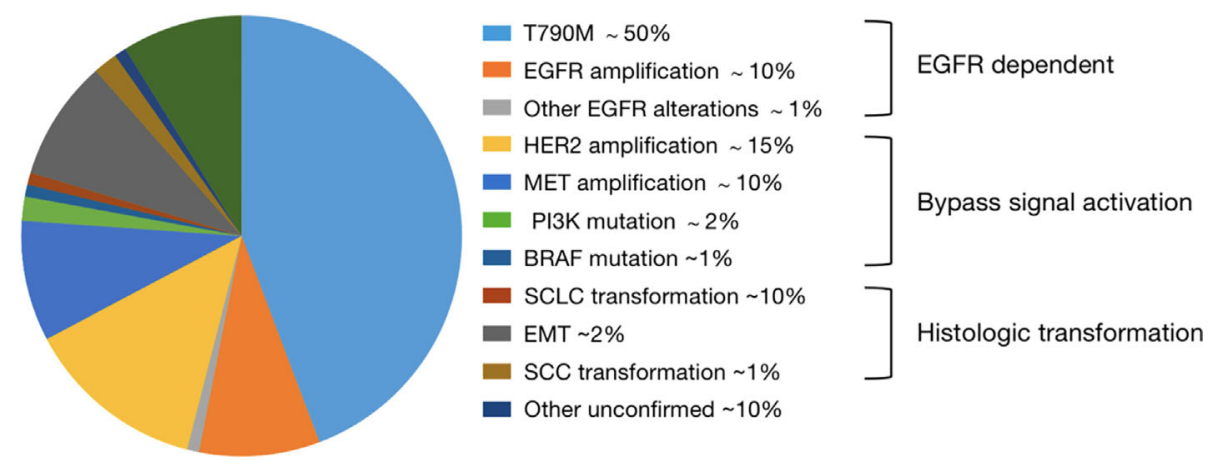

FIGURE 1 | Mechanisms of acquired resistance to first- and second-generation EGFR TKIs. 
amplifications of genes involving receptors [such as Insulin-like growth factor 1 receptor (IGF1R)], mutations or amplifications of genes involved in MAPK-PI3K signaling cascades (such as BRAF) and histologic transformation/phenotypic change have been reported (30-34). When osimertinib was administered as a front-line therapy, MET amplification ranked first, detected in $15 \%$ of patients by next-generation sequence ctDNA analysis (34). Moreover, MET amplification could also represent a potential mechanism of intrinsic resistance to osimertinib (38). HER 2 amplification occurred in $2 \%$ of cases and has been reported in one patient who experienced intrinsic resistance to osimertinib $(34,38)$. In terms of MAPK-PI3K pathway activation, KRAS $\mathrm{G} 12 \mathrm{D}$ has been reported after disease progression both in first-line and subsequent lines of therapy (33-35). Then, the BRAF V600E mutation has been identified as a resistance mechanism to osimertinib in $3 \%$ of cases both in first- and latter-line therapy (33-35). PIK3CA mutations E453K, E545K, and H1047R were identified in six cases, with E545K being the most represented in $4 \%$ of cases, and HER 2 mutation was detected in $1 \%$ of cases, which is different from HER2 amplification $(34,39)$.

HER2 alterations have been reported as resistance mechanisms to osimertinib, including amplifications and mutations, which are distinct molecular targets (39). However, they are mainly inframe exon 20 insertions. In a case reported by Hsu et al., an exon 16 skipping HER2 deletion (HER2D16), inducing resistance to osimertinib in a patient who is EGFR T790M-positive, was presented (40). The HER2D16 alteration has only previously been reported in breast adenocarcinoma, in which it was recognized to activate Src kinase signaling in approximately half of HER2-positive breast cancers (41). Different from breast cancers, expressing HER2D16 generates osimertinib resistance to EGFR T790M/L858R-mutant NSCLC cells in a Src-independent fashion through Src-bypass signaling, which was insensitive to Src inhibition with or without osimertinib $(40,41)$. They revealed that combined osimertinib and pan-HER small molecular inhibitor, afatinib, may synergistically overcome resistance to osimertinib in H1975-HER2D16 cells (40). Of note, Ichihara et al. reported that Src family kinases (SFK) and focal adhesion kinase (FAK) can sustain AKT and MAPK pathway signaling under continuous EGFR inhibition in osimertinib sensitive cells and inhibiting either the MAPK pathway or the AKT pathway enhanced the effects of osimertinib (42). Amplification of YES1, encoding SFK member YES1, has been reported as a resistance mechanism to osimertinib in NSCLC cell lines $(42,43)$. In addition, YESassociated protein (YAP) is the main mediator of the Hippo (also known as the Salvador-Warts-Hippo) signaling pathway, overexpression of which in NSCLC is associated with cancer progression, drug resistance, metastasis and poor prognosis (4245). Another emerging key player involved in osimertinib intrinsic resistance is the RTK Anexelekto (AXL), which can interact with other RTKs, including EGFR and HER3, and sustain survival of tumor cells exposed to osimertinib $(38,46)$. Overexpression of $A X L$ is also linked to EMT-associated resistance to osimertinib (44-46). Acquired oncogenic fusions and acquired cell cycle gene alterations occurred in 1-8 and 10\% respectively (34). To date, nearly $50 \%$ of resistant mechanisms in first-line are still not clear. Main mechanisms of resistance to first-line use of third-generation EGFR TKIs were summarized in Figure 2A, and we and we present them more vividly in Figure 3.

\section{Second Line}

Resistance will also inevitably happen after using thirdgeneration EGFR TKIs in second-line, EGFR-dependent or -independent (Figure 2B). EGFR tertiary mutations, T790M loss, EGFR amplification, and EGF overexpression are EGFRdependent alterations. EGFR C797S/G, G796S/R/D, L792F/H/Y, L798I, L718Q, E709K, G724S, L844V, V802F, L692V, G719 have been reported as EGFR tertiary mutations to cause acquired resistance to second-line use of osimertinib (30-32, 35, 47-50). The most common tertiary EGFR mutation is EGFR C797S, which occurs in exon 20 and accounts for $10-26 \%$ of cases of resistance to second-line osimertinib treatment $(21,35,47,48)$. Besides C797X mutations, a number of other rare point mutations in EGFR listed above have also been identified. Moreover, in second-line treatment, amplification of wild-type EGFR allele in addition to the presence of the EGFR ex19del allele was detected as a novel mechanism of resistance (49). Ex20ins mutation has also been reported in one patient after failure of second-line osimertinib therapy, and other mutations within exon 20 occurring after progression to osimertinib haven't been established yet (35).

In terms of EGFR-independent resistance, alterations including MET, HER2, and fibroblast growth factor receptor (FGFR) amplification, bypass signal activation including RASMAPK/ERK and PI3K-AKT pathway and histologic transformation/phenotypic change have been verified (30-33, $35,38,49-51)$. In the AURA3 study, the loss of T790M was experienced by $43 \%$ of patients, whereas $57 \%$ retained the mutation (35). Osimertinib has demonstrated superior efficacy against HER2 amplification through inhibiting downstream signaling pathway targets in genetically modified mice models in a preclinical trial $(48,51)$. However, activation of HER2 or $M E T$ was also identified in osimertinib resistant patients (30-33, 35). Overexpression of HER2 or MET in cells can persistently activate ERK and AKT as a result of sharing part of the same downstream pathways as EGFR (30-33, 35, 50). MET amplification can occur with or without loss of the T790M mutation in second-line setting of osimertinib, which was observed in nearly $19 \%$ of the samples at disease progression (35). Also, MET amplification co-occurred with EGFR C797S in $7 \%$ of cases (35). Different from MET, HER2 can indirectly activate PI3K and amplification of HER2 appears to mutually exclusive with T790M in EGFR-mutated NSCLC patients who develop resistance $(35,49,50)$. HER2 amplification has been identified in $5 \%$ of patients who have acquired resistance to second-line osimertinib (35). The combination of osimertinib and trastuzumab-emantisine has previously been shown to overcome HER2 amplification-mediated resistance in EGFR T790M-positive NSCLC cell lines (52). Osimertinib combining 
A

$1.0 \%$

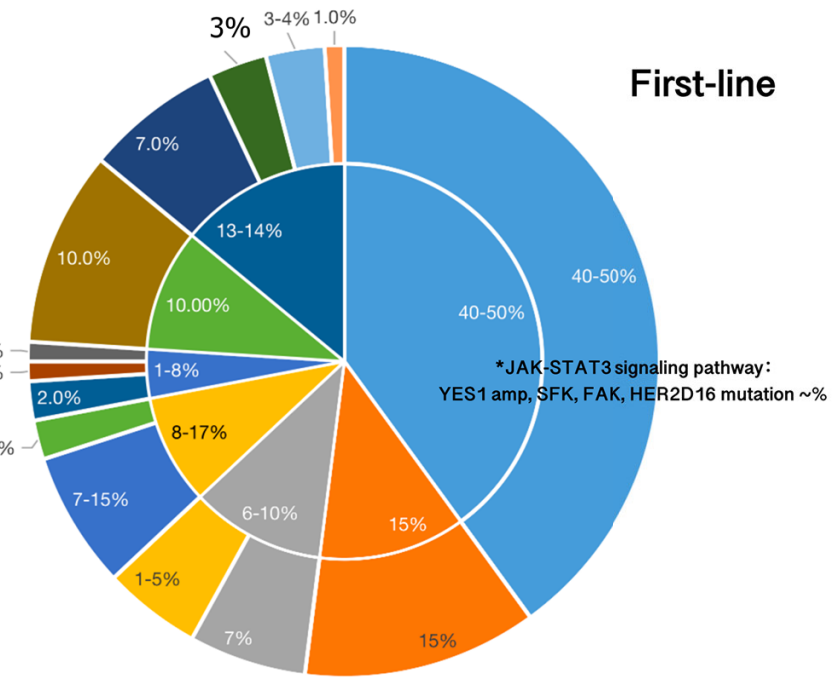

- Unknown

" Histologic transformation

= L7180,EGFR amp, G724S,S7681,E709K,L692V,L798

- MEE amp

- RET fusion

- BRAF tusion

- SPTBN1-ALK

- Other gene
- P13KCA

- BRAF VGO0

- KRAS
- Unknown

Histologic transformation

- EGFR mutations

- Acquired amplifications

- Oncogenic fusions

- Other gene alterations

- MAPK-PI3K signal activation
B

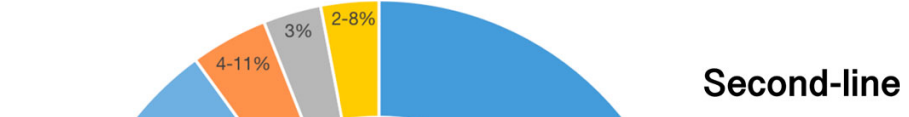

$1.00 \%$

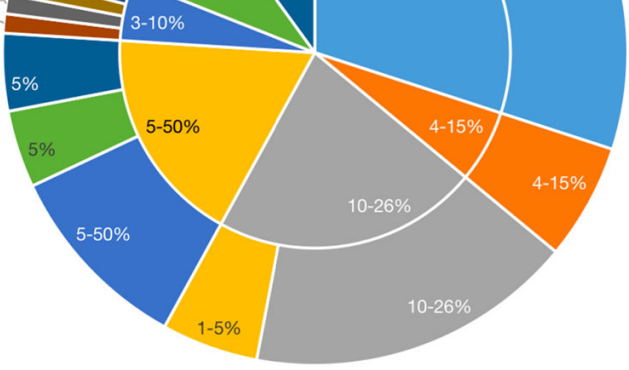

- Unknown

C.797x

L792X,G7966x,L7180,EGFR amp,ex20ins,other tertianry mutations - Unknown

- MET amp $\quad$ Histologic transformation

- HER2 amp

EGFR tertiary mutations

- FGFF3 tusion

- RET tusion

Acquired amplification

Oncogenic fusions

MAPK-PI3K signal activation

BRAF fusion

FIGURE 2 | (A) Main mechanisms of resistance to first-line setting of third-generation EGFR TKIs; (B). Main mechanisms of resistance to second-line setting of third-generation EGFR TKls. 


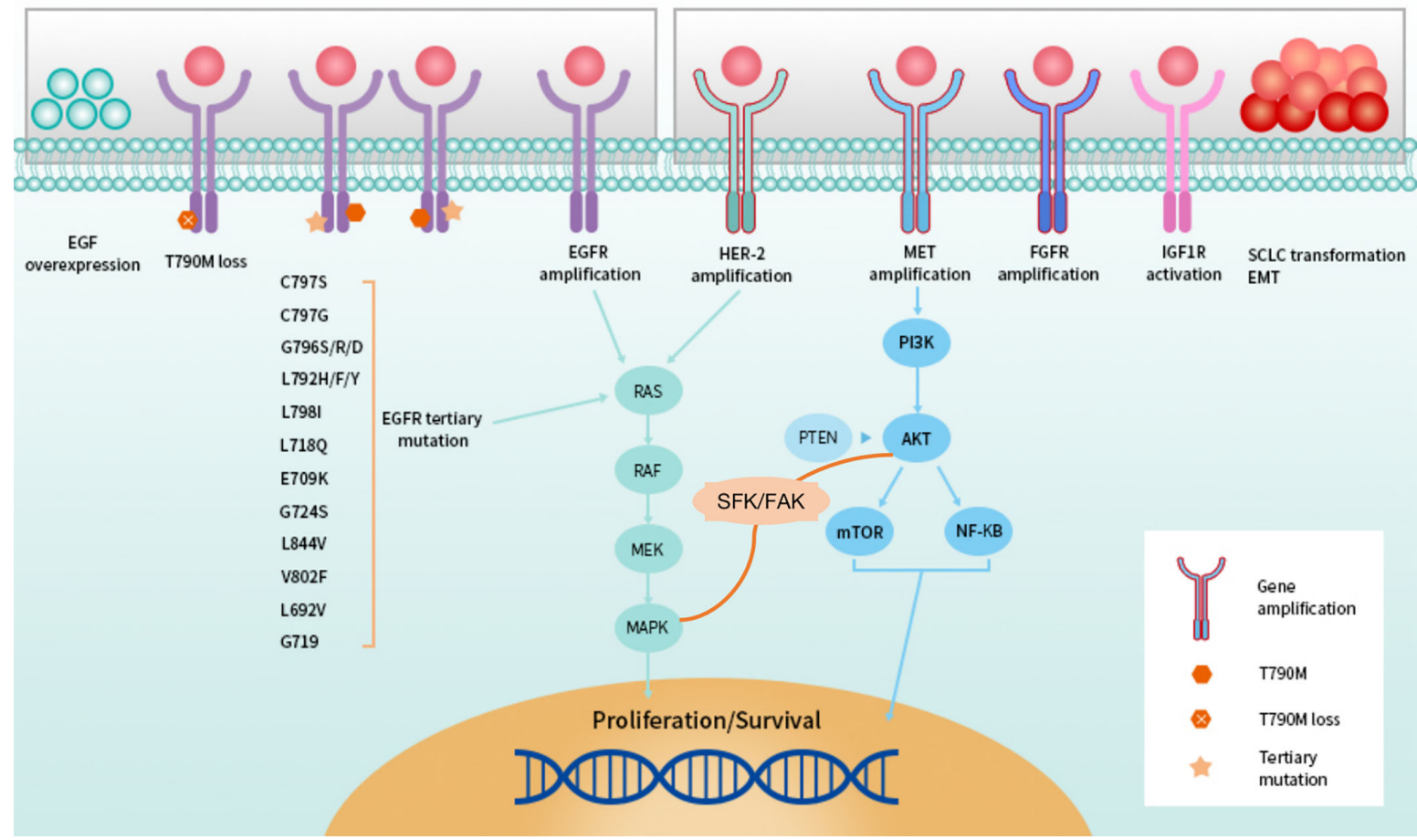

FIGURE 3 | EGFR-dependent and -independent resistance to second-line setting of third-generation EGFR TKIs.

with c-Met inhibitors, such as crizotinib, has been found effective in osimertinib-resistant EGFR-mutated NSCLC patients harboring $M E T$ amplification and more combination strategies will be discussed later $(38,53)$. Other resistance mechanisms to second-line osimertinib are similar to first-line, which may be presented in different proportions. We list them in Figure 2B.

\section{TREATMENT OPTIONS AFTER RESISTANCE OF THIRD-GENERATION EFGR TKIS}

Just like resistance of first- and second-generation EGFR TKIs, progress after drug resistance can be divided into oligosis and broad progress $(18,31)$. Continuation of EGFR TKIs plus local treatment is the first recommendation if oligosis (18). Re-biopsy should be adopted to identify the exact mechanism of acquired resistance to direct latter treatment. However, successful tissue biopsy is often not feasible, which is an invasive procedure associated with morbidity and may be limited by patient refusal, insufficient sample for molecular testing, tumor location, and performance status of patients $(54,55)$. Moreover, misdiagnosis may be caused by intra-tumor heterogeneity and spatiotemporal variation within the same patient (56). Thus, T790M testing at clinical progression on a first-line EGFR TKI, using plasma circulating tumor DNA (ctDNA) testing has been recommended for its advantage of being non-invasive, which is also referred to as liquid biopsy (57-59). The viable approach has also enabled serial monitoring with repeated molecular analyses at multiple time points. In addition to ctDNA, cell-free DNA (cfDNA) and circulating tumor cell (CTC) in peripheral blood are also tumorderived resources for liquid biopsy, which can be detected by various methods, including NGS, cobas EGFR mutation test, therascreen EGFR amplification refractory mutation system (ARMS), droplet digital polymerase chain reaction (ddPCR) and bead, emulsion, amplification and magnetics (BEAMing) (58-61). However, high rates of false negative ctDNA T790M have been observed across the AURA clinical trials with positive percentage agreement (PPA) of $51 \%$ in AURA3 (62). Based on this, it is recommended to repeat a tissue biopsy for patients with a negative plasma T790M result when feasible $(57,63)$. Of note, Sequist et al. reported that six patients who were directly treated with osimertinib after rociletinib resistance achieved partial response (PR) or stable disease (SD), and three patients with central nervous system (CNS) progression during rociletinib treatment received good control of CNS lesions after receiving osimertinib treatment (64). It suggests that rociletinib resistance may be due to incomplete targeted inhibition, and osimertinib can reverse this resistance, including CNS progress (64). In several clinical cases, platinum-based doublet chemotherapy was used to treat osimertinib-resistant patients with SCLC histologic transformation (30). Compared with osimertinibsensitive cells, osimertinib-resistant cells with SCLC histologic transformation were more sensitive to paclitaxel (30). This finding 
suggested that paclitaxel might be a favorable option for osimertinib-resistant patients harboring SCLC histologic transformation (30). In addition to these, newer generation EGFR TKIs and combination therapies have become the most promising options. We have summarized major coping strategies which we found in literature in Figure 4.

\section{NEWER GENERATION EGFR TKIS}

To overcome acquired resistance of third-generation EGFR TKIs, an allosteric inhibitor EAI045 targeting T790M and C797S mutation was reported in Nature in 2016 (65). It binds to the allosteric sites in the tyrosine kinase molecule to change the conformation of the enzyme, thereby inhibiting the enzymatic reaction $(65,66)$. EAI045 has different potency for the two subunits of EGFR asymmetric dimer, and cannot inhibit dimerization-mediated signal activation $(65,66)$. EAI045 single drug has a weak inhibitory effect, but can make tumor remission in the rat lung cancer model when combined with cetuximab (65, 66). In addition, EAI045 combined with cetuximab is effective for L858R/T790M, but has no inhibitory effect on ex19del/T790M, which is mainly due to the fact that L858R can expand and the allosteric domain of tyrosine kinase, while 19del prevents the opening of the allosteric domain of the enzyme molecule $(65,66)$. The researchers call this phenomenon mutation specificity. These data were limited to laboratories, and whether they can be translated into clinical benefits still needs further research. Recently, other fourth generation EGFR TKIs EAI001 and JBJ04-125-02 were reported, and more clinical trials are needed to evaluate their efficacy and safety profiles $(66,67)$. Furthermore, the aforementioned amivantamab (JNJ-61186372) is also a fourth generation EGFR TKI, which has shown preclinical activity in TKI-sensitive EGFR-mutated NSCLC models and in the ongoing CHRYSALIS study (68). Then, Cho et al. have also characterized the antitumor activity of amivantamab in multiple preclinical models harboring EGFR exon20ins mutations (29).

\section{CONVENTIONAL COMBINATIONS OF THIRD-GENERATION EGFR TKIS AND OTHER AGENTS}

Before ICIs were added, there were many traditional combination options with EGFR TKIs, including chemotherapy, other inhibitors, anti-EGFR monoclonal antibodies and anti-angiogenic target drugs. Although superior efficacy of combination of EGFR TKIs and chemotherapy was revealed, there existed controversies in the efficacy of EGFR TKIs plus chemotherapy in EGFR TKI-resistant NSCLC patients in clinical trials on previous generations of EGFR TKIs (69-71). In the mass, no apparent survival benefits were seen in such mode. Safety data were reported of an ongoing Japanese phase II trial of osimertinib with carboplatin/pemetrexed, and a phase I study of osimertinib with platinum and etoposide is currently recruiting (NCT03567642) (72). We are not optimistic about the results.

Whether the C797S and T790M mutations are in the same allele makes important biological significance. In vitro studies have reported C797S and T790M mutations in trans (on separate alleles) are sensitive to a combination of first- and thirdgeneration TKIs whereas if C797S and T790M mutations are both in cis (on the same allele), EGFR TKIs alone or in combination are ineffective $(33-35,37,47,48)$. Based on this, combination of first-generation TKIs and osimertinib can overcome resistance of osimertinib when the C797S and T790M mutations are in different alleles $(47,48)$. Combination therapy trials of Nazartinib with gefitinib (NCT0329213, NCT03333343) and of osimertinib with gefitinib (NCT03122717) and dacomitinib

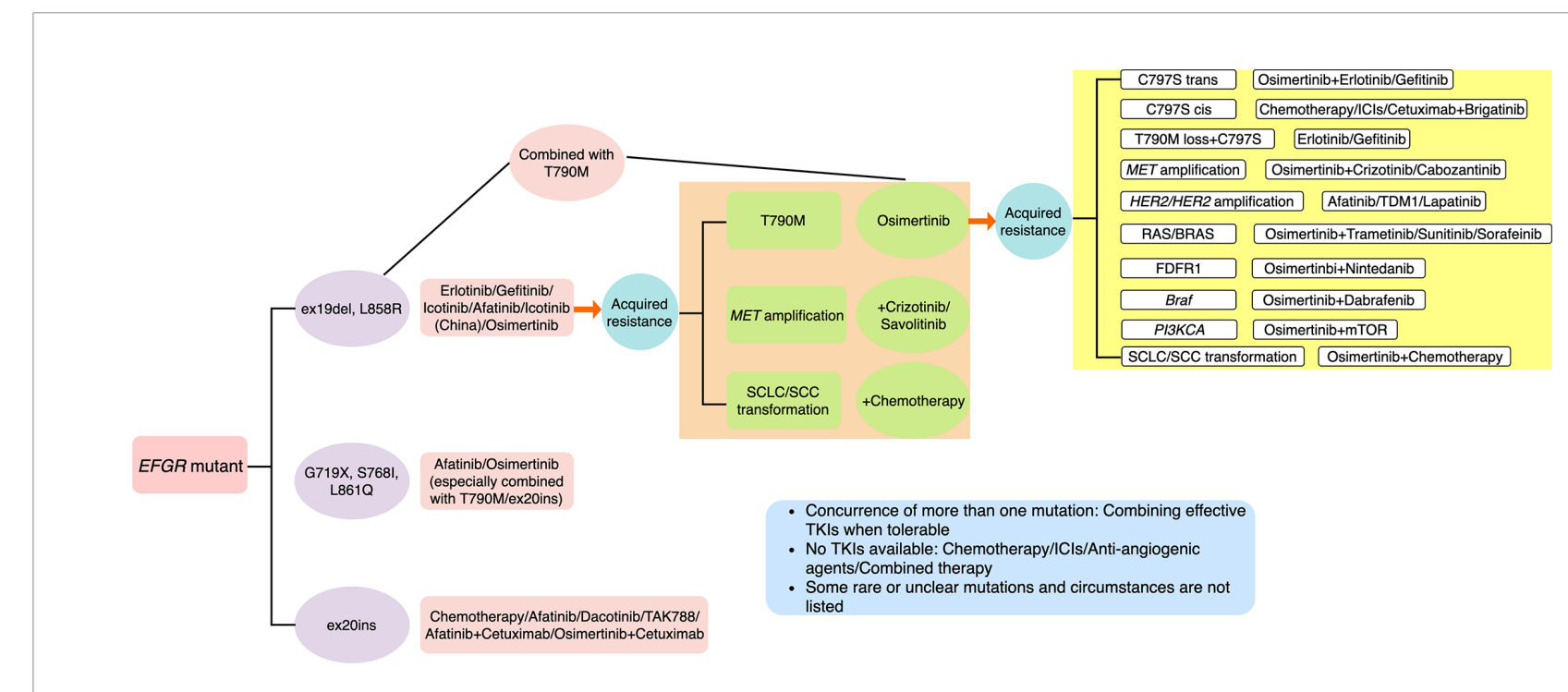

FIGURE 4 | Summary of major resistance mechanisms to osimertinib and coping strategies which we found in literature. Some rare or unclear mutations and circumstances are not listed. 
(NCT03810807) are currently underway to verify the hypothesis that combining first- and third-generation EGFR TKIs may delay the C797S and T790M resistance mutations. Combinations of third-generation EGFR TKIs and other targeted agents were attempts based on heterogeneous resistance mechanisms. Cell experiments have shown that osimertinib combined with MEK inhibitor selumetinib can delay the emergence of drug resistance, and a phase I trial (NCT03392246) of osimertinib combined with selumetinib in the treatment of EGFR-mutant advanced NSCLC patients is ongoing. Furthermore, the TATTON study (NCT02143466) has reported recently that combination of osimertinib and savolitinib (AZD6094) showed acceptable riskbenefit profile and encouraging anti-tumor activity in patients with EGFR mutation-positive, MET-amplified, advanced NSCLC, who had disease progression on a previous EGFR TKIs (73). Based on data from TATTON, the SAVANNAH study (NCT03778229) further evaluating the combination of osimertinib and savolitinib in patients with $M E T$-driven resistance to osimertinib is ongoing. In addition, the multi-drug, biomarker-directed, phase II platform ORCHARD trial (NCT03944772) is ongoing and evaluating resistance mechanisms and combination treatment options for patients with EGFR-mutant NSCLC who have progressed on first-line osimertinib therapy, including osimertinib and savolitinib, for patients with acquired MET amplification. The potential of osimertinib and savolitinib as a novel treatment option for patients with acquired MET amplification who are EGFR mutation-positive will be better assessed by these subsequent phase II studies. To date, numerous combined strategies with third-generation EGFR TKIs such as trastuzumab emtansine (T-DM1), JAK1 inhibitor, AXL inhibitor and BRAF V600E inhibitor are currently investigated in clinical trials $(52,74$, 75). Inhibition of AXL kinase activity restored both $\mathrm{CDH} 1$ expression and sensitivity to EGFR TKIs $(44,45)$. A recent research study revealed that $\mathrm{AXL}$ overexpression was associated with a poor response to osimertinib, whereas combination treatment with an AXL inhibitor and osimertinib prevented the development of intrinsic resistance to osimertinib and the subsequent emergence of resistant clones in vitro and in vivo (46). Therefore, AXL remains a promising next line therapeutic target for EMT-associated resistance, with several pharmacological inhibitors in early clinical development (ClinicalTrials.gov identifiers NCT03255083, NCT02424617, NCT02729298). As far as we are concerned, strategies to overcome resistance to osimertinib should be individualized for diverse mechanisms on the basis of tissue or liquid biopsy. Meanwhile, we have to say that such combinations may make limited overall benefits in the general population before the arrival of an efficient newer generation of EGFR TKIs and how to add ICIs may be a better direction of efforts.

\section{ICIS}

\section{Argument About the Interactions of the Oncogenes and Tumor Microenvironment}

ICIs, hot representative of immunotherapy, are epoch-making in treatment of NSCLC, benefiting from the study of the tumor microenvironment (TME). However, at present, ICIs are not suitable for everyone, and patient selection for ICIs depends mainly on some molecular biomarkers currently, such as programmed cell death protein 1 (PD-1), programmed deathligand 1 (PD-L1), tumor mutational burden (TMB), CD8+ T cell infiltration, Tim-3, and so on (76-78). Even so, known markers are not reliable enough to predict the efficacy yet. In recent years, several ICIs have been approved in patients with negative driver genes, PD-L1 expression or without screening, but the performance in the positive driver genes seems to be unsatisfactory (79). PD-L1 expression has been reported to be associated with EGFR mutations in NSCLC (79-84). In murine NSCLC models, EGFR signaling induced by EGFR mutations activated PD-L1 expression and induced immune escape, and PD-L1 expression was down-regulated by EGFR TKIs treatment (81). In theory, the rapid release of antigen through dying tumor cells under TKIs could enhance the inflammatory response (82). The data published by $\mathrm{Wu}$ showed that the proportion of primary resistance to EGFR TKIs was higher in PD-L1-positive patients, suggesting that these patients may benefit from ICIs (83). In other words, strong PD-L1 expression predicted a poor response to EGFR TKIs and might be associated with de novo resistance to targeted therapy in first line therapy (84). However, others hold conflicting views (85). Similarly, conflicting results have been obtained in clinical trials of combining ICIs with EGFR TKIs in treatment of NSCLC. It's worth mentioning that it's also possible that there may be no relationship between the oncogenes and TME, or multiple oncogene mutations are needed to predict efficacy of ICIs. Concept of genomic mutation signature (GMS) consisting of eight genes was proposed as a better predictive tool lately, which needs further research (86). In addition, serious side effects are often seen in EGFR-mutant NSCLC patients treated with ICIs, which might arise from interactions of the oncogenes and TME. Clarifying the relationships between them and lessening adverse reactions deserve further investigations. We have summarized studies on efficacy and safety profiles of ICIs in EGFR-mutant NSCLC patients in Table $\mathbf{1}$.

\section{ICI Monotherapy}

Data derived from subgroup analysis of large clinical trials have revealed that different agents seemed to have different impacts, but in general, the clinical activity of ICI monotherapy in firstline treatment of EGFR-mutant NSCLC was limited (87-90, 107). More studies focused on the role of ICIs in second-line treatment of EGFR-addicted NSCLC patients after TKIs resistance, which we also concern about. The IIIb/IV safety trial CheckMate 153 of nivolumab in patients with advanced or metastatic squamous or non-squamous NSCLC who received at least one prior line found that partial response rate was only $11 \%(\mathrm{n}=55)$ in the EGFR-mutated subgroup compared with $16 \%(\mathrm{n}=300)$ in the EGFR wild-type subgroup (108). A metaanalysis assessing the role of ICIs (nivolumab, pembrolizumab and atezolizumab) as second-line therapy in EGFR-driven advanced NSCLC, including three trials (CheckMate 057, KEYNOTE-010 and POPLAR study), concluded that EGFRmutant patients didn't benefit from ICIs over docetaxel in terms of OS (91). Another systematic review and meta-analysis 
TABLE 1 | Efficacy and safety profiles of immune checkpoint inhibitors in EGFR-mutant non-small cell lung cancer patients.

\begin{tabular}{|c|c|c|c|c|c|c|c|}
\hline Category & Study & Therapy & & & Efficacy & Safety & Reference \\
\hline \multirow[t]{8}{*}{ Immune monotherapy } & $\begin{array}{l}\text { CheckMate } 012 \\
\text { (First-line) }\end{array}$ & $\mathrm{O}$ & I & $8(15 \%)$ & $\begin{array}{l}\text { ORR } 14 \text { vs 30\% (Wildtype). } \\
24 \text { weeks PFS 14\% vs. 51\% (Wildtype) }\end{array}$ & Tolerable & $(87)$ \\
\hline & $\begin{array}{l}\text { KEYNOTE-001 } \\
\text { (Previously treated) }\end{array}$ & $\mathrm{K}$ & 1 & $74(17 \%)$ & $\begin{array}{l}\text { mOS } 6.0 \text { vs. } 11.9 \text { months } \\
\text { 5-year OS } 7.9 \text { vs. } 16.4 \%\end{array}$ & Tolerable & (88) \\
\hline & NCT03513666 & K & $\|$ & - & No response & - & (89) \\
\hline & $\begin{array}{ll}\mathrm{BIRCH} & \mathrm{No} \mathrm{CT} \\
& 1 \mathrm{CT} \\
& \geq 2 \mathrm{CT}\end{array}$ & $\mathrm{T}$ & $\|$ & $\begin{array}{l}13(11 \%) \\
18(8 \%) \\
14(7 \%)\end{array}$ & $\begin{array}{l}\text { ORR } 23 \text { vs 19\% (Wildtype). } \\
\text { ORR } 0 \text { vs. } 21 \% \\
\text { ORR } 7 \text { vs. } 35 \%\end{array}$ & Tolerable & (90) \\
\hline & $\begin{array}{l}\text { CheckMate } 057 \\
\text { (Second-line) }\end{array}$ & $\mathrm{O}$ & III & $82(14 \%)$ & $\begin{array}{l}\text { HR } 1.18 \text { (0.45-2.07) vs. } 0.66 \text { (0.51-0.85) } \\
\text { (Docetaxel) }\end{array}$ & - & $(91,92)$ \\
\hline & $\begin{array}{l}\text { KEYNOTE-010 } \\
\text { (Second-line) }\end{array}$ & $\mathrm{K}$ & $\begin{array}{l}\text { II/ } \\
\text { III }\end{array}$ & $86(8 \%)$ & $\begin{array}{l}\text { HR } 0.88 \text { (0.45-1.72) vs. } 0.66 \text { (0.55-0.79) } \\
\text { (Docetaxel) }\end{array}$ & & \\
\hline & $\begin{array}{l}\text { POPLAR } \\
\text { (Second-line) }\end{array}$ & $\mathrm{T}$ & $\|$ & $18(6 \%)$ & $\begin{array}{l}\text { HR } 0.99 \text { (0.29-3.40) vs. } 0.70 \text { (0.47-1.04) } \\
\text { (Docetaxel) }\end{array}$ & & \\
\hline & $\begin{array}{l}\text { OAK } \\
\text { (Second-line) }\end{array}$ & $\mathrm{T}$ & III & $85(10 \%)$ & $\begin{array}{l}\text { HR } 1.24 \text { (0.71-2.18) vs. } 0.69 \text { (0.57-0.83) } \\
\text { (Docetaxel) }\end{array}$ & & \\
\hline Third-line or later & ATLANTIC & 1 & $\|$ & $\begin{array}{l}111(\text { EGFR } \\
+/ A L K+)\end{array}$ & $\begin{array}{l}\text { (PD-L1 } \geq 25 \%) \\
\text { ORR } 12.2 \% \text { (95\% Cl } 5.7 \text { to } 21.8) \\
\text { mPFS } 1.9 \text { months } \\
\text { mOS } 13.3 \text { months }\end{array}$ & Tolerable & (93) \\
\hline \multirow{3}{*}{$\begin{array}{l}\text { Immunization combined } \\
\text { with EGFR TKls }\end{array}$} & TATTON & $\mathrm{I}+\mathrm{OSI}$ & 1 & - & - & Severe & (94) \\
\hline & CAUREL & I+OSI & III & - & - & Severe & (95) \\
\hline & CheckMate 012 & O+Erlo & 1 & $\begin{array}{c}20 \text { (TKI treated) } \\
1(\mathrm{TKI} \\
\text { untreated) }\end{array}$ & $\begin{array}{l}\text { ORR } 15 \% \text { (1 CR), DCR 65\%, } \\
\text { No PD-L1 ORR } 0 \\
2.2 \text { months PR } \\
\text { CR } 27 \text { months }\end{array}$ & & $(96,97)$ \\
\hline \multirow{7}{*}{$\begin{array}{l}\text { Immunization combined with } \\
\text { chemotherapy and anti-angiogenic } \\
\text { therapy }\end{array}$} & \multirow{2}{*}{$\begin{array}{l}\text { A retrospective } \\
\text { study }\end{array}$} & $\mathrm{O}+\mathrm{CT}$ & - & 5 & $45.5 \%$ & Tolerable & (98) \\
\hline & & $\mathrm{K}+\mathrm{CT}$ & - & 6 & $\begin{array}{l}\text { mPFS } 7.47 \text { months } \\
1 \text { year OS } 54.5 \%\end{array}$ & & \\
\hline & IMpower150 & $\begin{array}{l}\mathrm{ABCP} \\
\mathrm{BCP}\end{array}$ & III & $\begin{array}{c}35(8.8 \%) \\
45(11.3 \%)\end{array}$ & $\begin{array}{l}\text { mOS } 29.4 \text { months } \\
\text { mOS } 18.1 \text { months }\end{array}$ & Tolerable & $(99,100)$ \\
\hline & - & $\begin{array}{l}\text { Toripalimab } \\
+\mathrm{CT}\end{array}$ & $\|$ & - & $\begin{array}{l}50 \% \\
\text { mPFS } 7 \text { months }\end{array}$ & Tolerable & $(101)$ \\
\hline & KEYNOTE-789 & $\mathrm{K}+\mathrm{CT}$ & III & - & Ongoing & - & $(102)$ \\
\hline & CheckMate 722 & $\mathrm{O}+\mathrm{CT}$ & III & - & Ongoing & - & (103) \\
\hline & WJOG8515L & $\mathrm{O}$ & $\|$ & - & Ongoing & - & (104) \\
\hline \multirow[t]{2}{*}{ Combined immunity } & \multirow{2}{*}{$\begin{array}{l}\text { CheckMate } 012 \\
\text { KEYNOTE-021 }\end{array}$} & O+Ipili & 1 & 8 (10.4\%) & ORR 50\% & Tolerable & (105) \\
\hline & & $\mathrm{K}+\| l i l i$ & 1 & $10(22 \%)$ & ORR 10\% & Tolerable & (106) \\
\hline
\end{tabular}

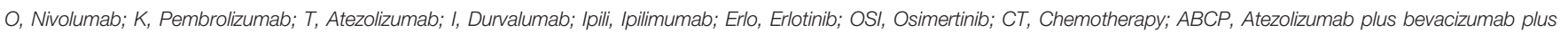

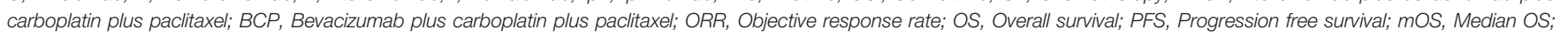
mPFS, median PFS; CR, Complete response; HR, Hazard ratio.

of four trails (OAK was added) drew the same conclusion (92). Indeed, these studies have their limitations as EGFR mutation was not determined by centralized testing, but reflect some of the truth. Of note, the phase II trial ATLANTIC evaluated the effectiveness of durvalumab in second-line and above treatment of patients with locally advanced or metastatic EGFR-mutant NSCLC who had experienced at least two regimens of chemotherapy or EGFR TKIs (93). In patients with $E G F R+/ A L K+$ and $\geq 25 \%$ tumor cells expression of PDL1, the ORR and median OS were $12.2 \%$ and 13.3 months, which were significantly better lpagthan chemotherapy (93). As a whole, although durvalumab has revealed a distinct advantage compared to chemotherapy in ATLANTIC trial, ICIs haven't achieved a desired effect in treatment of EGFR-mutant NSCLC, neither first- nor second-setting.

\section{ICls Combined With EGFR TKIs}

Based on the unsatisfactory efficacy of monotherapy in patients with EGFR mutations, whether ICIs can become a successful assistant of TKIs in combination mode has become a hot topic. D'Incecco et al. reported that elevated PD-L1 levels are associated with EGFR mutations and EGFR TKIs treatment, suggesting that the combination of anti-PD-1/PD-L1, and EGFR TKIs might have synergistic effects in NSCLC therapy (80). The TATTON study showed that treatment with durvalumab combined with osimertinib in treated patients with EGFR mutations was associated with an increased risk of poisoning (94). The phase III clinical trial CAUREL comparing the effects of durvalumab combined with osimertinib with osimertinib alone in T790M-positive NSCLC patients who have been treated with EGFR TKIs and found that the incidence of EGFR TKI-associated interstitial pneumonitis in both EGFR TKI and nivolumab cohort was much higher than TKI single drug cohort (95). More, a longer PFS (2.1 months) in the T790M-negative patients than the T790M-positive patients (1.3 months) was seen, and the former also had a higher proportion of tumors with a PD-L1 expression along with higher CD8+ tumor infiltration and TMB (95). Many other combination strategies 
with addition of ICIs to targeted TKIs were proven to induce significant treatment-related toxicities without significantly improved efficacy (109-111). As part of phase I clinical trial CheckMate 012 , twenty who have received with erlotinib and one TKI-naive EGFR-mutant NSCLC patients were treated with nivolumab plus erlotinib, and the trial concluded that nivolumab plus erlotinib was tolerable and made durable responses in EGFR-mutant, TKI-treated NSCLC patients (96, 97). In conclusion, combined treatment of EGFR TKIs and ICIs is still at an early stage, and further efforts to assess different combinations are necessary. At present, given that the efficacy of combining PD-1/PD-L1 inhibitors with EGFR TKIs as an option for EGFR-mutant advanced NSCLC patients is still not very clear, and serious adverse reactions seem inevitable, clinicians need to weight the advantages and corresponding disadvantages when making decisions.

\section{ICls Combined With Chemotherapy and Anti-Angiogenic Therapy}

Broadly speaking, the efficacy and safety of ICIs combined with TKIs are not very satisfactory. Nevertheless, ICIs combined with chemotherapy and anti-angiogenic therapy have been a major research direction. ICIs combined with platinum-based chemotherapy have been the currently recommended first-line treatment for advanced EGFR-/ALK- NSCLC (18). A small retrospective study showed that ORR of combined treatment of ICIs and chemotherapy was 45.5\%, median PFS was 7.47 months, and 1-year survival rate was $54.5 \%$ in patients treated by chemotherapy combined with pembrolizumab (6) and nivolizumab (5) on osimertinib resistance (98). Of course, the result still needs to be validated by large prospective trials for its small sample. The blockbuster study IMpower 150 (NCT02366143) showed that the combination of atezolizumab and bevacizumab conferred synergistic efficacy to patients with metastatic non-squamous NSCLC in terms of PFS and median OS, regardless of EGFR or ALK aberration or the expression of PD-L1 (99). Socinski et al. have reported the final OS analyses from Impower150 for ACP (Arm A, atezolizumab + carboplatin + paclitaxel) vs BCP (Arm C, carboplatin + paclitaxel + bevacizumab) and found that in patients with EGFR+/ALK + tumors, OS was comparable in Arms A (ACP, atezolizumab + carboplatin + paclitaxel) and $\mathrm{C}(\mathrm{BCP}$, carboplatin + paclitaxel + bevacizumab) (97). However, continued OS benefit was seen in Arm B (ABCP, atezolizumab + carboplatin + paclitaxel + bevacizumab) vs $\mathrm{C}$ in these subgroups, and the safety profile of each regimen was consistent with previously reported data at the second interim OS analysis $(99,100)$. Noteworthy, Impower150 study is currently the only randomized, prospective phase III clinical trial to demonstrate efficacy of ICIs in oncogene-addicted NSCLC patients. Furthermore, a phase II study of toripalimab combined with chemotherapy has demonstrated a higher ORR of $50 \%$ and longer median PFS of 7 months in EGFR-mutant advanced NSCLC patients who failed to prior EGFR TKIs therapies, which provides a novel choice for such patients (101). The KEYNOTE-789, CheckMate 722, and WJOG8515L trials are ongoing enrolling advanced non-squamous NSCLC and
EGFR-mutant patients who progressed on prior TKIs therapies, and patients were assigned to receive chemotherapy alone or combined with ICIs. We look forward to good results in the future (102-104).

\section{Combined ICls}

The current research data on the combination of ICI and ICI for EGFR mutation-positive patients are insufficient. CheckMate 227 has confirmed the long and lasting benefits in OS by combing nivolumab and ipilimumab (112). More, an open-label, multicenter, randomized phase III clinical study CheckMate-9LA has found obvious benefits in OS without new safety concerns in treatment of nivolumab plus ipilimumab plus chemotherapy (113). However, both of them excluded the presence of EGFR mutations or known $A L K$ translocations. In CheckMate 012, eight patients with EGFR mutations without chemotherapy received nivolumab combined with ipilimumab, and the ORR was 50\% (105). Cohort D and H of KEYNOTE-021 reported an ORR of only $10 \%$ in TKIs-pretreated EGFR-mutant NSCLC patients by combined treatment of pembrolizumab and ipilimumab (106). Thus, conclusions were inconsistent in terms of remission rate, and we must be careful of serious adverse reactions. More combinations need to be explored, especially for patients pretreated with osimertinib. It seems that how to reduce side effects in setting of ICIs is particularly important, either single or combined.

\section{CONCLUSIONS AND PERSPECTIVES}

Third-generation EGFR TKI osimertinib has confirmed its position both in first-line and second-line after resistance to previous generations of TKI treatment in EGFR-mutant advanced NSCLC patients. However, almost all patients will face resistance to osimertinib, and the mechanisms are complex and diverse, none of which exceeds $20 \%$. In our view, although there are some other treatment options reported, three main strategies to cope with resistance to osimertinib are next generation EGFR TKIs, conventional combinations of EGFR TKIs and other agents and treatment combined with ICIs. Firstly, next generation EGFR TKIs EAI045, EAI001, JBJ-04-125-02 and amivantamab are in the research phase and need to be verified in more trials, but we have seen great potential. Then, benefiting from extensive study of mechanisms involved in resistance development to thirdgeneration EGFR TKIs, we could combine osimertinib with chemotherapy, other oncogene inhibitors, anti-EGFR monoclonal antibodies and anti-angiogenic agents based on specific resistance mechanism. We imagine that future research will keep laying emphasis on resistance mechanisms to EGFR TKIs, and unknown mechanisms of resistance deserve urgent elucidation with thirdgeneration agents widely used in the first line, primary or acquired. The last, to offer patients with oncogene addiction the chance of ICIs induced long-term control of disease, many novel combinations with ICIs have been explored and have made some breakthroughs. From our point of view, ICIs combined with chemotherapy and anti-angiogenic agents are by far the most 
promising mode, which may be due to release of antigen through killed tumor cells and deserve further study. Of course, given that serious adverse reactions have become a major obstacle in further promotion of many combination modes, we should strive to identify causes of such side effects and learn to lessen them. In general, further understanding of interactions of oncogenes and TME, relationships between multiple markers, a more accurate predictive model, novel combinations and control of adverse reactions are future directions of efforts. Of course, immunotherapy is not limited to ICIs, which has enormous potential to be tapped. Notably, biopsy again after resistance of third-generation EGFR TKIs is particularly crucial as its guiding role in next treatment. Based on this, it's important to develop noninvasive biomarker tests persistently, which may impinge on a greater fraction of NSCLC patients.

\section{REFERENCES}

1. Shigematsu H, Lin L, Takahashi T, Nomura M, Suzuki M, Wistuba II, et al. Clinical and biological features associated with epidermal growth factor receptor gene mutations in lung cancers. J Natl Cancer Inst (2005) 97:33946. doi: 10.1093/jnci/dji055

2. Shi Y, Au JS, Thongprasert S, Srinivasan S, Tsai CM, Khoa MT, et al. A prospective, molecular epidemiology study of EGFR mutations in Asian patients with advanced non-small-cell lung cancer of adenocarcinoma histology (PIONEER). J Thorac Oncol (2014) 9(2):154-62. doi: 10.1097/ JTO.0000000000000033

3. Zhang YL, Yuan JQ, Wang KF, Fu XH, Han XR, Threapleton D, et al. The prevalence of EGFR mutation in patients with non-small cell lung cancer: a systematic review and meta-analysis. Oncotarget (2016) 7(48):78985-93. doi: 10.18632/oncotarget.12587

4. Rosell R, Moran T, Queralt C, Porta R, Cardenal F, Camps C, et al. Screening for epidermal growth factor receptor mutations in lung cancer. $N$ Engl J Med (2009) 361(10):958-67. doi: 10.1056/NEJMoa0904554

5. Barlesi F, Mazieres J, Merlio J-P, Debieuvre D, Mosser J, Lena H, et al. Biomarkers France Contributors. Routine molecular profiling of patients with advanced non-small-cell lung cancer: results of a 1-year nationwide programme of the French Cooperative Thoracic Intergroup (IFCT). Lancet (2016) 387:1415-26. doi: 10.1016/S0140-6736(16)00004-0

6. Cancer Genome Atlas Research N. Comprehensive molecular profiling of lung adenocarcinoma. Nature (2014) 511(7511):543-50. doi: 10.1038/nature13385

7. Bazley LA, Gullick WJ. The epidermal growth factor receptor family. Endocr Relat Cancer (2005) 12(Suppl 1):S17-27. doi: 10.1677/erc.1.01032

8. Shigematsu H, Gazdar AF. Somatic mutations of epidermal growthfactor receptor signaling pathway in lung cancers. Int J Cancer (2006) 118:257-62. doi: $10.1002 / \mathrm{ijc} .21496$

9. Yang JC, Shih JY, Su WC, Hsia TC, Tsai CM, Ou SH, et al. Afatinib for patients with lung adenocarcinoma and epidermal growth factor receptor mutations (LUX-Lung 2): a phase 2 trial. Lancet Oncol (2012) 13(5):539-48. doi: 10.1016/S1470-2045(12)70086-4

10. Yang JC-H, Sequist LV, Lucien Geater S, Tsai CM, Mok TS, Schuler M, et al. Clinical activity of afatinib in patients with advanced non-small-cell lung cancer harbouring uncommon EGFR mutations: a combined post-hoc analysis of LUX-Lung 2, LUX-Lung 3, and LUX-Lung 6. Lancet Oncol (2015) 16:830-8. doi: 10.1016/S1470-2045(15)00026-1

11. Arteaga CL, Engelman JA. ERBB receptors: from oncogene discovery to basic science to mechanism-based cancer therapeutics. Cancer Cell (2014) 25 (3):282-303. doi: 10.1016/j.ccr.2014.02.025

12. Sequist LV, Waltman BA, Dias-Santagata D, Digumarthy S, Turke AB, Fidias $\mathrm{P}$, et al. Genotypic and histological evolution of lung cancers acquiring resistance to EGFR inhibitors. Sci Transl Med (2011) 3:75ra26. doi: 10.1126/ scitranslmed.3002003

\section{AUTHOR CONTRIBUTIONS}

LW determined the writing direction and was responsible for the manuscript writing and modification. LK was responsible for literature collection and collation. ZZ took part in making charts. JY gave ideas and suggestions on selecting directions. XM provided financial support and review and revise manuscript. All authors contributed to the article and approved the submitted version.

\section{FUNDING}

This work was supported by National Natural Science Foundation of China (81972864).

13. Yu HA, Arcila ME, Rekhtman N, Sima CS, Zakowski MF, Pao W, et al Analysis of tumor specimens at the time of acquired resistance to EGFR-TKI therapy in 155 patients with EGFR-mutant lung cancers. Clin Cancer Res (2013) 19:2240-7. doi: 10.1158/1078-0432.CCR-12-2246

14. Zhou W, Ercan D, Chen L, Yun CH, Li D, Capelletti M, et al. Novel mutantselective EGFR kinase inhibitors against EGFR T790M. Nature (2009) 462:1070-4. doi: 10.1038/nature08622

15. Sequist LV, Soria J-C, Goldman JW, Wakelee HA, Gadgeel SM, Varga A, et al. Rociletinib in EGFR-Mutated Non-Small-Cell Lung Cancer. N Engl J Med (2015) 372:1700-9. doi: 10.1056/NEJMoa1413654

16. Janne PA, Ramalingam SS, Yang JC-H, Ahn M-J, Kim D-W, Kim S-W, et al. Clinical activity of the mutant-selective EGFR inhibitor AZD9291 in patients (pts) with EGFR inhibitor-resistant non-small cell lung cancer (NSCLC). J Clin Oncol (2014) 32:abstract 800. doi: 10.1200/jco.2014.32.15_suppl.8009

17. Lu S, Wang QM, Zhang GJ, Dong X, Yang CT, Song Y, et al. The Third Generation EGFR Inhibitor (EGFR-TKI) HS-10296 in Advanced NSCLC Patients with Resistance to First Generation EGFR-TKI [EB/OL]. WCLC (2019), abstract OA02.03. doi: 10.1016/j.jtho.2019.08.413

18. Na National Comprehensive Cancer Network (NCCN) and NCCN Clinical Practice Guidelines in Oncology (NCCN Guidelines). Non-small cell lung cancer. Version 6. (2020) June 15, 2020 Available at: https://www.nccn.org.

19. Jänne PA, Yang JCH, Kim DW, Planchard D, Ohe Y, Ramalingam SS, et al AZD9291 in EGFR inhibitor-resistant non-small-cell lung cancer. $N$ Engl J Med (2015) 372:1689-99. doi: 10.1056/NEJMoa1411817

20. Yang J, Ramalingam SS, Jänne PA, Jänne PA, Cantarini M, Mitsudomi T, et al. LBA2_ PR: Osimertinib (AZD9291) in pre-treated pts with T790Mpositive advanced NSCLC: updated Phase 1 (P1) and pooled Phase 2 (P2) results. J Thorac Oncol (2016) 11:S152-5. doi: 10.1016/S1556-0864(16) 30325-2

21. Mok TS, Wu YL, Ahn MJ, Garassino MC, Kim HR, Ramalingam SS, et al. Osimertinib or Platinum-Pemetrexed in EGFR T790M-Positive Lung Cancer. N Engl J Med (2017) 376:629-40. doi: 10.1056/NEJMoa1612674

22. Soria JC, Ohe Y, Vansteenkiste J, Reungwetwattana T, Chewaskulyong B, Lee $\mathrm{KH}$, et al. Osimertinib in Untreated EGFR-Mutated Advanced NonSmall-Cell Lung Cancer. N Engl JMed (2018) 378:113-25. doi: 10.1056/ NEJMe1714580

23. Ahn MJ, Kim DW, Cho BC, Kim SW, Lee JS, Ahn JS, et al. Activity and safety of AZD3759 in EGFR-mutant non-small-cell lung cancer with CNS metastases (BLOOM): a phase 1, open-label, dose-escalation and doseexpansion study. Lancet Respir Med (2017) 5:891e902. doi: 10.1016/S22132600(17)30378-8

24. Hoffknecht P, Tufman A, Wehler T, Pelzer T, Wiewrodt R, Schütz M, et al. Efficacy of the irreversible ErbB family blocker afatinib in epidermal growth factor receptor (EGFR) tyrosine kinase inhibitor (TKI)-pretreated non-small-cell lung cancer patients with brain metastases or leptomeningeal disease. J Thorac Oncol (2015) 10:156e163. doi: 10.1097/JTO.0000000000000380 
25. Cho JH, Lim SH, An HJ, Kim KH, Park KU, Kang EJ, et al. Osimertinib for patients with non-small-cell lung cancer harboring uncommon EGFR mutations: a multicenter, open-label, phase II trial (KCSG-LU15-09). J Clin Oncol (2020) 38 (Feb. 5):488-95. doi: 10.1200/JCO.19.00931

26. Chiu CH, Yang CT, Shih JY, Huang MS, Su WC, Lai RS, et al. Epidermal growth factor receptor tyrosine kinase inhibitor treatment response in advanced lung adenocarcinomas with G719X/L861Q/S768I mutations. J Thorac Oncol (2015) 10:793-9. doi: 10.1093/annonc/mdu349.7

27. Yun J, Hong MH, Kim SY, Park CW, Kim S, Yun MR, et al. YH25448, an irreversible EGFR-TKI with potent intracranial activity in EGFR mutant non-small cell lung cancer. Clin Cancer Res (2019) 25:2575-87. doi: 10.1158/ 1078-0432.CCR-18-2906

28. Ahn M-J, Han J-Y, Lee KH, Kim S-W, Kim D-W, Lee Y-G. Lazertinib in patients with EGFR mutation-positive advanced non-small-cell lung cancer: results from the dose escalation and dose expansion parts of a first-inhuman, open-label, multicentre, phase 1-2 study. Lancet Oncol (2019) 20:1681-90. doi: 10.1016/S1470-2045(19)30504-2

29. Cho BC, Lee KH, Cho EK, Kim D, Lee J, Han J, et al. Amivantamab (JNJ61186372), an EGFR-MET bispecific antibody, in combination with lazertinib, a 3rd-generation tyrosine kinase inhibitor (TKI), in advanced EGFR NSCLC. Ann Oncol (2020) 31(suppl_4):S754-840. doi: 10.1016/ j.annonc.2020.08.1572

30. Kim TM, Song A, Kim DW, Kim S, Ahn YO, Keam B, et al. Mechanisms of acquired resistance to AZD9291: a mutation-selective, irreversible EGFR inhibitor. J Thorac Oncol (2015) 10:1736-44. doi: 10.1097/JTO.0000000000000688

31. Tang Z-H, Lu J-J. Osimertinib resistance in non-small cell lung cancer: Mechanisms and therapeutic strategies. Cancer Lett (2018) 420:242-6. doi: 10.1016/j.canlet.2018.02.004

32. Le X, Puri S, Negrao MV, Nilsson MB, Robichaux J, Boyle T, et al. Landscape of EGFR-dependent and -independent Resistance mechanisms to osimertiniband continuation therapy beyond progression in EGFR-mutant NSCLC. Clin Cancer Res (2018) 24(24):6195-203. doi: 10.1158/10780432.CCR-18-1542

33. Le X, Puri S, Negrao MV, Nilsson MB, Robichaux J, Boyle T, et al. Tissue-based molecular and histological landscape of acquired resistance to osimertinib given initially or at relapse in patients with EGFR-mutant lung cancers. J Clin Oncol (2019) 37:9028-8. doi: 10.1200/JCO.2019.37.15_suppl.9028

34. Ramalingam SS, Cheng Y, Zhou C, Ohe Y, Imamura F, Cho BC, et al. LBA50Mechanisms of acquired resistance to first-line osimertinib: Preliminary data from the phase III FLAURA study. Ann Oncol (2018) 29. doi: $10.1093 /$ annonc/mdy424.063

35. Papadimitrakopoulou VA, Wu Y-L, Han J-Y, Ahn M-J, Ramalingam SS, John T, et al. LBA51Analysis of resistance mechanisms to osimertinib in patients with EGFR T790M advanced NSCLC from the AURA3 study. Ann Oncol (2018) 29(suppl 8):mdy424.064. doi: 10.1093/annonc/mdy424.064

36. Weng CH, Chen LY, Lin YC, Shih JY, Lin YC, Tseng RY, et al. Epithelialmesenchymal transition (EMT) beyond EGFR mutations per se is a common mechanism for acquired resistance to EGFR TKI. Oncogene (2019) 38 (4):455-68. doi: 10.1038/s41388-018-0454-2

37. Niederst MJ, Hu H, Mulvey HE, Lockerman EL, Garcia AR, Piotrowska Z, et al. The allelic context of the C797S mutation acquired upon treatment with third-generation EGFR inhibitors impacts sensitivity to subsequent treatment strategies. Clin Cancer Res (2015) 21:3924-33. doi: 10.1158/10780432.CCR-15-0560

38. Ortiz-Cuaran S, Scheffler M, Plenker D, Dahmen L, Scheel AH, FernandezCuesta L, et al. Heterogeneous Mechanisms of Primary and Acquired Resistance to Third-Generation EGFR Inhibitors. Clin Cancer Res (2016) 22:4837-47. doi: 10.1158/1078-0432.CCR-15-1915

39. Li BT, Ross DS, Aisner DL, Chaft JE, Hsu M, Kako SL, et al. HER2 amplification and HER2 mutation are distinct molecular targets in lung cancers. J Thorac Oncol (2016) 11:414-9. doi: 10.1016/j.jtho.2015.10.025

40. Hsu C-C, Liao B-C, Liao W-Y, Markovets A, Stetson D, Thress K, et al. Exon-16-skipping HER2 as a novel mechanism of osimertinib-resistance in EGFR L858R/T790M-positive non-small-cell lung cancer. J Thorac Oncol (2020) 15:50-61. doi: 10.1016/j.jtho.2019.09.006

41. Castagnoli L, Ghedini GC, Koschorke A, Triulzi T, Dugo M, Gasparini P, et al. Pathobiological implications of the d16HER2 splice variant for stemness and aggressiveness of HER2-positive breast cancer. Oncogene (2017) 36:1721-32. doi: 10.1038/onc.2016.338

42. Ichihara E, Westover D, Meador CB, Yan Y, Bauer JA, Lu P, et al. SFK/FAK signaling attenuates osimertinib efficacy in both drug-sensitive and drugresistant models of egfr-mutant lung cancer. Cancer Res (2017) 77:29903000. doi: 10.1158/0008-5472.CAN-16-2300

43. Fan P-D, Narzisi G, Jayaprakash AD, Venturini E, Robine N, Smibert P, et al. YES1 amplification is a mechanism of acquired resistance to EGFR inhibitors identified by transposon mutagenesis and clinical genomics. Proc Natl Acad Sci U S A (2018) 115:E6030-8. doi: 10.1073/pnas.1717782115

44. Tung J-N, Lin P-L, Wang Y-C, Wu DW, Chen CY, Lee H. PD-L1 confers resistance to EGFR mutation-independent tyrosine kinase inhibitors in nonsmall cell lung cancer via upregulation of YAP1 expression. Oncotarget (2017) 9:4637-46. doi: 10.18632/oncotarget.23161

45. McGowan M, Kleinberg L, Halvorsen AR, Helland A, Brustugun OT. NSCLC depend upon YAP expression and nuclear localization after acquiring resistance to EGFR inhibitors. Genes Cancer (2017) 8:497-504. doi: $10.18632 /$ genesandcancer.136

46. Taniguchi H, Yamada T, Wang R, Tanimura K, Adachi Y. Nishiyam, A. et al. AXL confers intrinsic resistance to osimertinib and advances the emergence of tolerant cells. Nat Commun (2019) 10:259. doi: 10.1038/s41467-01808074-0

47. Thress KS, Paweletz CP, Felip E, Cho BC, Stetson D, Dougherty B, et al. Acquired EGFR C797Smutation mediates resistance to AZD9291 in nonsmall cell lung cancer harboring EGFR T790M. Nat Med (2015) 21(6):560-2. doi: $10.1038 / \mathrm{nm} .3854$

48. Oxnard GR, Hu Y, Mileham KF, Husain H, Costa DB, Tracy P, et al. Assessment of resistance mechanisms and clinical implications in patients with EGFRT790M-positive lung cancer and acquired resistance to osimertinib. JAMA Oncol (2018) 4(11):1527-34. doi: 10.1001/jamaoncol. 2018.2969

49. Knebel FH, Bettoni F, Shimada AK, Cruz M, Alessi JV, Negrão MV, et al. Sequential liquid biopsies reveal dynamic alterations of EGFR driver mutations and indicate EGFR amplification as a new mechanism of resistance to osimertinib in NSCLC. Lung Cancer (2017) 108:238-41. doi: 10.1016/j.lungcan.2017.04.004

50. Piotrowska Z, Niederst MJ, Karlovich CA, Wakelee HA, Neal JW, MinoKenudson M, et al. Heterogeneity underlies the emergence of EGFR T790 wild-type clones following treatment of T790M-positive cancers with a third-generation EGFR inhibitor. Cancer Discov (2015) 5:713-22. doi: 10.1158/2159-8290.CD-15-0399

51. Liu S, Li S, Hai J, Wang X, Chen T, Quinn MM, et al. Targeting HER2 aberrations in non-small cell lung cancer with osimertinib. Clin Cancer Res (2018) 24(11):2594-604. doi: 10.1158/1078-0432.CCR-17-1875

52. La Monica S, Cretella D, Bonelli M, Fumarola C, Cavazzoni A, Digiacomo G, et al. Trastuzumab emtansine delays and overcomes resistance to the thirdgeneration EGFR-TKI osimertinib in NSCLC EGFR mutated cell lines. J Exp Clin Cancer Res (2017) 36(1):174. doi: 10.1186/s13046-017-0653-7

53. Shi P, Oh Y-T, Zhang G, Yao W, Yue P, Li Y, et al. Met gene amplification and protein hyperactivation is a mechanism of resistance to both first and third generation EGFR inhibitors in lung cancer treatment. Cancer Lett (2016) 380:494-504. doi: 10.1016/i.canlet.2016.07.021

54. Chouaid C, Dujon C, Do P, Monnet I, Madroszyk A, Le Caer H, et al. Feasibility and clinical impact of re-biopsy in advanced non small-cell lung cancer: a prospective multicenter study in a real-world setting (GFPC study 12-01). Lung Cancer (2014) 86:170-3. doi: 10.1016/j.lungcan.2014.08.016

55. Kim TO, Oh IJ, Kho BG, Park HY, Chang JS, Park CK, et al. Feasibility of rebiopsy and EGFR mutation analysis in patients with non-small cell lung cancer. Thorac Cancer (2018) 9(7):856-64. doi: 10.1111/1759-7714.12762

56. de Bruin EC, McGranahan N, Swanton C. Analysis of intratumor heterogeneity unravels lung cancer evolution. Mol Cell Oncol (2015) 2: e985549. doi: 10.4161/23723556.2014.985549

57. Kalemkerian GP, Narula N, Kennedy EB, Biermann WA, Donington J, Leighl NB, et al. Molecular testing guideline for the selection of patients with lung cancer for treatment with targeted tyrosine kinase inhibitors: American Society of Clinical Oncology Endorsement of the College of American Pathologists/International Association for the Study of Lung Cancer/ 
Association for Molecular Pathology Clinical Practice Guideline Update. J Clin Oncol (2018) 36:911-9. doi: 10.1200/JCO.2017.76.7293

58. Sundaresan TK, Sequist LV, Heymach JV, Riely GJ, Janne PA, Koch WH, et al. Detection of T790M, the acquired resistance EGFR mutation, by tumor biopsy versus noninvasive blood-based analyses. Clin Cancer Res (2016) 22:1103-10. doi: 10.1158/1078-0432.CCR-15-1031

59. Jenkins S, Yang JC, Ramalingam SS, Yu K, Patel S, Weston S, et al. Plasma ctDNA analysis for detection of the EGFR T790M mutation in patients with advanced non-small cell lung cancer. J Thorac Oncol (2017) 12(7):1061-70. doi: 10.1016/j.jtho.2017.04.003

60. Jamal-Hanjani M, Wilson GA, Horswell S, Mitter R, Sakarya O, Constantin T, et al. Detection of ubiquitous and heterogeneous mutations in cell-freeDNA from patients with early-stage non-small-cell lung cancer. Ann Oncol (2016) 27(5):862-7. doi: 10.1093/annonc/mdw037

61. Turetta M, Bulfoni M, Brisotto G, Fasola G, Zanello A, Biscon-tin E, et al. Assessment of the mutational status of NSCLC using hypermetabolic circulating tumor cells. Cancers (Basel) (2018) 10(8):270. doi: 10.3390/ cancers 10080270

62. Wu YL, Jenkins S, Ramalingam S, Han J-Y, Delmonte A, Hsia T-C, et al. MA08.03 osimertinib vs platinum-pemetrexed for T790M-Mutation positive advanced NSCLC (AURA3): plasma ctDNA analysis. $J$ Thorac Oncol (2019) 12:S386. doi: 10.1016/j.jtho.2016.11.436

63. Novello S, Barlesi F, Califano R, Cufer T, Ekman S, Levra MG, et al. Metastatic non-small-cell lung cancer: ESMO clinical practice guidelines for diagnosis, treatment and follow-up. Ann Oncol (2016) 27:v1-v27. doi: 10.1093/annonc/mdw326

64. Sequist LV, Piotrowska Z, Niederst MJ, Heist RS, Digumarthy S, Shaw AT, et al. Osimertinib Responses After Disease Progression in Patients Who Had Been Receiving Rociletinib. JAMA Oncol (2016) 4:541-3. doi: 10.1001/ jamaoncol.2015.5009

65. Jia Y, Yun CH, Park E, Ercan D, Manuia M, Juarez J, et al. Overcoming EGFR (T790M) and EGFR(C797S) resistance with mutant-selective allosteric inhibitors. Nature (2016) 534:129-32. doi: 10.1038/nature17960

66. Wang S, Song Y, Liu D. EAI045: The fourth-generation EGFR inhibitor overcoming T790M and C797S resistance. Cancer Lett (2017) 385:51-4. doi: 10.1016/j.canlet.2016.11.008

67. To C, Jang J, Chen T, Park E, Mushajiang M, De Clercq DJH, et al. Single and Dual Targeting of Mutant EGFR With an Allosteric Inhibitor. Cancer Discov (2019) 9(7):926-43. doi: 10.1158/2159-8290.CD-18-0903

68. Yun J, Lee S-H, Kim S-Y, Jeong S-Y, Kim J-H, Pyo K-H, et al. Antitumor Activity of Amivantamab (JNJ-61186372), an EGFR-MET Bispecific Antibody, in Diverse Models of EGFR Exon 20 Insertion-Driven NSCLC. Cancer Discov (2020) 8:1194-209. doi: 10.1158/1538-7445.AM2020-5199

69. Laurila N, Koivunen JP. EGFR inhibitor and chemotherapy combinations for acquired TKI resistance in EGFR-mutant NSCLC models. Med Oncol (2015) 32(7):205. doi: 10.1007/s12032-015-0627-6

70. Soria JC, Wu YL, Nakagawa K, Kim SW, Yang JJ, Ahn MJ, et al. Gefitinib plus chemotherapy versus placebo plus chemotherapy in EGFR-mutationpositive non-small-cell lung cancer after progression on first-line gefitinib (IMPRESS): a phase 3 randomised trial. Lancet Oncol (2015) 16(8):990-8. doi: 10.1016/S1470-2045(15)00121-7

71. Mok T, Kim SW, Wu YL, Nakagawa K, Yang JJ, Ahn MJ, et al. Gefitinib plus chemotherapy versus chemotherapy in epidermal growth factor receptor mutation-positive non-small-cell lung cancer resistant to first-line gefitinib (IMPRESS): overall survival and biomarker analyses. J Clin Oncol (2017) 35 (36):4027-34. doi: 10.1200/JCO.2017.73.9250

72. Okada M, Tanaka K, Asahina H, Morita S, Maemondo M, Seike M, et al. Safety analysis of an open label, randomized phase 2 study of osimertinib alone versus osimertinib plus carboplatin-pemetrexed for patients with nonsmall cell lung cancer (NSCLC) that progressed during prior epidermal growthfactor receptor (EGFR) tyrosine kinase inhibitor (TKI) therapy and which harbors a T790M mutation of EGFR. J Clin Oncol (2018) 36:e21073. doi: 10.1200/JCO.2018.36.15_suppl.e21073

73. Sequist LV, Han J-Y, Ahn M-J, Cho BC, Yu H, Kim SW, et al. Osimertinib plus savolitinib in patients with EGFR mutation-positive, MET-amplified, non-small-cell lung cancer after progression on EGFR tyrosine kinase inhibitors: interim results from a multicentre, open-label, phase $1 \mathrm{~b}$ study. Lancet Oncol (2020) 21(3):373-86. doi: 10.1016/S1470-2045(19)30785-5
74. Andrews Wright NM, Goss GD. Third-generation epidermal growth factor receptor tyrosine kinase inhibitors for the treatment of non-small cell lung cancer. Transl Lung Cancer Res (2019) 8(Suppl 3):S247-64. doi: 10.21037/ tlcr.2019.06.01

75. Lim SM, Syn NL, Cho BC, Soo RA. Acquired resistance to EGFR targeted therapy in non-small cell lung cancer: Mechanisms and therapeutic strategies. Cancer Treat Rev (2018) 65:1-10. doi: 10.1016/j.ctrv.2018.02.006

76. Yarchoan M, Hopkins A, Jaffee EM. Tumor mutational burden and response rate to PD-1 inhibition. N Engl J Med (2017) 377:2500-1. doi: 10.1056/ NEJMc1713444

77. Tumeh PC, Harview CL, Yearley JH, Shintaku IP, Taylor EJM, Robert L, et al. PD-1 blockade induces responses by inhibiting adaptive immune resistance. Nature (2014) 515:568-71. doi: 10.1038/nature13954

78. Sundar R, Soong R, Cho BC, Brahmer JR, Soo RA. Immunotherapy in the treatment of non-small cell lung cancer. Lung Cancer (2014) 85:101-9. doi: 10.1016/j.lungcan.2014.05.005

79. Soo RA, Kim HR, Asuncion BR, Fazreen Z, Omar MFM, Herrera MC, et al. Significance of immune checkpoint proteins in EGFR-mutant non-small cell lung cancer. Lung Cancer (2017) 105:17-22. doi: 10.1016/j.lungcan.2017.01.008

80. D’Incecco A, Andreozzi M, Ludovini V, Rossi E, Capodanno A, Landi L, et al. PD-1 and PD-L1 expression in molecularly selected non-small-cell lung cancer patients. Br J Cancer (2015) 112:95-102. doi: 10.1038/bjc.2014.555

81. Akbay EA, Koyama S, Carretero J, Altabef A, Tchaicha JH, Christensen CL, et al. Activation of the PD-1 pathway contributes to immune escape in EGFR-driven lung tumors. Cancer Discov (2013) 3:1355-63. doi: 10.1158/ 1535-7163.TARG-13-B290

82. Moschella F, Proietti E, Capone I, Belardelli F. Combination strategies for enhancing the efficacy of immunotherapy in cancer patients. Ann NY Acad Sci (2010) 1194:169-78. doi: 10.1111/j.1749-6632.2010.05464.x

83. Su S, Dong ZY, Xie Z, Yan LX, Li YF, Su J, et al. Strong Programmed Death Ligand 1 Expression PredictsPoor Response and De Novo Resistance to EGFR Tyrosine Kinase Inhibitors Among NSCLC Patients With EGFR Mutation. J Thoracic Oncol (2018) 11:1668-75. doi: 10.1016/j.jtho.2018.07.016

84. Haratani K, Hayashi H, Tanaka T, Kaneda H, Togashi Y, Sakai K, et al. Tumor immune microenvironment and nivolumab efficacy in EGFR mutation-positive non-small-cell lung cancer based on T790M status after disease progression during EGFR-TKI treatment. Ann Oncol (2017) 28:1532-9. doi: 10.1093/annonc/mdx183

85. Lin C, Chen X, Li M, Liu J, Qi X, Yang W, et al. Programmed death-ligand 1 expression predicts 21 tyrosine kinase inhibitor response and better prognosis in a cohort of patients with epidermal growth factor receptor mutation-positive lung adenocarcinoma. Clin Lung Cancer (2015) 16:e2535. doi: $10.1016 /$ j.cllc.2015.02.002

86. Bai X, Wu DH, Ma SC, Wang J, Tang X-R, Kang S, et al. Development and validation of a genomic mutation signature to predict response to PD-1 inhibitors in non-squamous NSCLC: a multicohort stud. J Immunother Cancer (2020) 8:e000381. doi: 10.1136/jitc-2019-000381

87. Gettinger S, Rizvi NA, Chow LQ, Borghaei H, Brahmer J, Ready N, et al. Nivolumab monotherapy for first-line treatment of advanced non-small cell lung cancer. J Clin Oncol (2016) 34:2980-7. doi: 10.1200/JCO.2016.66.9929

88. Garon EB, Hellmann MD, Rizvi NA, Carcereny E, Leighl NB, Ahn M-J, et al. Five-Year Overall Survival for Patients With Advanced Non-Small-Cell Lung Cancer Treated With Pembrolizumab: Results From the Phase I KEYNOTE-001 Study. J Clin Oncol (2019) 37:2518-27. doi: 10.1200/JCO.19.00934

89. Lisberg A, Cummings A, Goldman JW, Bornazyan K, Reese N, Wang T, et al. A phase II study of pembrolizumab in EGFR-mutant, PD-L1+, tyrosine kinase inhibitor naïve patients with advanced NSCLC. J Thorac Oncol (2018) 13:1138-45. doi: 10.1016/j.jtho.2018.03.035

90. Peters S, Gettinger S, Johnson ML, Janne PA, Garassino MC, ChristophD, et al. Phase II Trial of Atezolizumab As First-Line or Subsequent Therapy for Patients With Programmed Death-Ligand 1-Selected Advanced NonSmall-Cell Lung Cancer (BIRCH). J Clin Oncol (2017) 35:2781-9. doi: 10.1200/JCO.2016.71.9476

91. Lee CK, Man J, Lord S, Links M, Gebski V, Mok T, et al. Checkpoint inhibitors in metastatic EGFR-mutated non-small cell lung cancer - a metaanalysis. J Thorac Oncol (2017) 12(2):403-7. doi: 10.1016/j.jtho.2016.10.007

92. Lee CK, Man J, Lord S, Links M, Gebski V, Mok T, et al. Clinical and molecular characteristics associated with survival among patients treated 
with checkpoint inhibitors for advanced non-small cell lung carcinoma. A systematic review and meta-analysis. JAMA Oncol (2018) 4:210-6. doi: 10.1001/jamaoncol.2017.4427

93. Garassino MC, Cho BC, Kim JH, Mazières J, Vansteenkiste J, Lena H, et al. Durvalumab as third-line or later treatment for advanced non-small-cell lung cancer (ATLANTIC): an open-label, single-arm, phase 2 study. Lancet Oncol (2018) 19:521-36. doi: 10.1016/S1470-2045(18)30144-X

94. Ahn M-J, Yang J, Yu H, Saka H, Ramalingam S, Goto K, et al. 136O: Osimertinib combined with durvalumab in EGFR-mutant non-small cell lung cancer: results from the TATTON phase Ib trial. J Thorac Oncol (2016) 11(4):S115. doi: 10.1016/S1556-0864(16)30246-5

95. Oshima Y, Tanimoto T, Yuji K, Tojo A. EGFR-TKI-associated interstitial pneumonitis in nivolumab-treated patients with non-small cell lung cancer. JAMA Oncol (2018) 4(8):1112-5. doi: 10.1001/jamaoncol.2017.4526

96. Antonia SJ, Rizvi NA, Chow LQ, Horn L, Gandhi L, Spigel DR, et al. Nivolumab (Anti-Pd-1; Bms-936558, Ono-4538) in combination with platinum-based doublet chemotherapy (Pt-Dc) or erlotinib in advanced non-small cell lung cancer (NSCLC). J Thorac Oncol (2014) 9(9):S153-3. doi: 10.1016/j.ijrobp.2014.08.024

97. Gettinger S, Hellmann MD, Chow L, Borghaei H, Antonia S, Brahmer JR, et al. Nivolumab plus erlotinib in patients with EGFR-mutant advanced NSCLC. J Thorac Oncol (2018) 13(9):1363-72. doi: 10.1016/j.jtho.2018.05.015

98. Yang B, Long YP, Hu Y. Chemoimmunotherapy combination: Potential option for metastatic NSCLC patients with EGFR mutation resistant to osimertinib. J Clin Oncol (2019) 37 (suppl; abstr e20618) doi: 10.1200/ JCO.2019.37.15_suppl.e20618

99. Socinski MA, Jotte RM, Cappuzzo F, Orlandi F, Stroyakovskiy D, Nogami N, et al. Atezolizumab for first-line treatment of metastatic nonsquamous NSCLC. N Engl JMed (2018) 378(24):2288-301. doi: 10.1056/NEJMoa1716948

100. Socinski MA, Mok TS, Nishio M, Jotte RM, Cappuzzo F, Orlandi F, et al. Abstract CT216: IMpower150 final analysis: Efficacy of atezolizumab (atezo) + bevacizumab (bev) and chemotherapy in first-line (1L) metastatic nonsquamous (nsq) non-small cell lung cancer (NSCLC) across key subgroups. Cancer Res (2020) 80(16 Supplement):CT216. doi: 10.1158/ 1538-7445.AM2020-CT216

101. Zhang J, Zhou C, Zhao Y, Mu X, Zhou J, Bao Z, et al. A PII study of toripalimab, aPD-1 mAb, in combination with chemotherapy in EGFR+ advanced NSCLC patients failed to prior EGFR TKI therapies. $J$ Thorac Oncol (2019) 14:S292. doi: 10.1016/j.jtho.2019.08.587

102. Riely G, Hui R, Carbone D, Park K, Carrigan M, Xu X, et al. Phase 3 study of pemetrexed-platinum with or without pembrolizumab for TKI-resistant/ EGFR-mutated advanced NSCLC: KEYNOTE-789. J Thorac Oncol (2018) 13:S494. doi: 10.1016/j.jtho.2018.08.637

103. Nakagawa K, Yang JCH, Park K. Checkmate 722: a phase 3 trial of nivolumab with chemotherapy or ipilimumab vs chemotherapy in epidermal growth factor receptor (EGFR)- mutation, T790M-negative stage IV or recurrent non-small cell lung cancer (NSCLC) after EGFR tyrosine kinase inhibitor (TKI) therapy. Ann Oncol (2016) 27(Suppl.9): ix139-56. doi: 10.1093/annonc/mdw594.045

104. Hayashi H, Chiba Y, Sakai K, Fujita T, Yoshioka H, Sakai D, et al. A randomized phase II study comparing nivolumab with carboplatinpemetrexed for patients with EGFR mutation-positive nonsquamous nonsmall-cell lung cancerwho acquire resistance to tyrosinekinase inhibitors not due to a secondary T790M mutation: rationale and protocol design for the WJOG8515L study. Clin Lung Cancer (2017) 18:719-23. doi: 10.1016/ j.cllc.2017.05.012

105. Hellmann MD, Rizvi NA, Goldman JW, Gettinger SN, Borghaei H, Brahmer JR, et al. Nivolumab plus ipilimumab as first-line treatment for advanced non-small-cell lung cancer (CheckMate 012): results of an open-label, phase 1, multicohort study. Lancet Oncol (2017) 18(1):31-41. doi: 10.1016/S14702045(16)30624-6

106. Gubens MA, Sequist LV, Stevenson JP, Powell SF, Villaruz LC, Gadgeel SM, et al. Pembrolizumab in combination with ipilimumab as second-line or later therapy for advanced non-small-cell lung cancer: KEYNOTE-021 cohorts D and H. Lung Cancer (2019) 130:59-66. doi: 10.1016/j.lungcan.2018.12.015

107. Spigel Dd. Impower110: Interim overall survival (OS) analysis of a phase III study of atezolizumab (atezo) vs platinum-based chemotherapy (chemo) as first-line (1L) treatment (tx) in PD-L1-selected NSCLC [C]. Barcelona: European Lung Cancer Congress (2019). doi: 10.1093/annonc/mdz293

108. Waterhouse D, Horn L, Reynolds C, Spigel D, Chandler J, Mekhail T, et al. Safety profile of nivolumab administered as 30-mininfusion: analysis of data from CheckMate 153. Cancer Chemother Pharmacol (2018) 81:679-86. doi: 10.1007/s00280-018-3527-6

109. Ma BBY, Rudin CM, Cervantes A. Preliminary safety and clinical activity of erlotinib plus atezolizumab from a Phase Ib study in advanced NSCLC. Ann Oncol (2016) 27(9 Suppl):mdw594.005. doi: 10.1093/annonc/mdw594.005

110. Oshima Y, Tanimoto T, Yuji K, Tojo A. EGFR-TKI-associated interstitial pneumonitis in nivolumab-treated patients with non-small cell lung cancer. JAMA Oncol (2018) 4(8):1112-5. doi: 10.1001/jamaoncol.2017.4526

111. Gibbons DL, Chow LQ, Kim D-W, Kim SW, Yeh T, Song X, et al. $57 \mathrm{O}$ Efficacy, safety and tolerability of MEDI4736 (durvalumab [D]), a human IgG1 anti-programmed cell death-ligand-1 (PD-L1) antibody, combined with gefitinib (G): a phase I expansion in TKI-naïve patients (pts) with EGFR mutant NSCLC. J Thorac Oncol (2016) 11(4):S79. doi: 10.1016/S15560864(16)30171-X

112. Hellmann MD, Paz-Ares L, Bernabe Caro R, Zurawski B, Kim S-W, Carcereny Costa E. Nivolumab plus Ipilimumab in Advanced Non-SmallCell Lung Cancer. N Engl J Med (2019) 21:2020-31. doi: 10.1056/ NEJMoa1910231

113. Reck M, Ciuleanu T-E, Dols MC, Schenker M, Zurawski B, Menezes J, et al. Nivolumab (NIVO) +ipilimumab (IPI) +2 cycles of platinum-doublet chemotherapy (chemo) vs 4 cycles chemo as first-line (1L) treatment (tx) for stage IV/recurrent non-small cell lung cancer (NSCLC): CheckMate 9LA [J]. J Clin Oncol (2020) 38(15_suppl):9501. doi: 10.1200/JCO.2020. 38.15_suppl.9501

Conflict of Interest: The authors declare that the research was conducted in the absence of any commercial or financial relationships that could be construed as a potential conflict of interest.

Copyright $\odot 2020 \mathrm{Wu}, \mathrm{Ke}$, Zhang, $\mathrm{Yu}$ and Meng. This is an open-access article distributed under the terms of the Creative Commons Attribution License (CC BY). The use, distribution or reproduction in other forums is permitted, provided the original author(s) and the copyright owner(s) are credited and that the original publication in this journal is cited, in accordance with accepted academic practice. No use, distribution or reproduction is permitted which does not comply with these terms. 